University of Nebraska - Lincoln

DigitalCommons@University of Nebraska - Lincoln

\title{
Dielectric constants and phonon modes of amorphous hafnium aluminate deposited by metal organic chemical vapor deposition
}

C. Bundesmann

Leibniz-Institut für Oberflächenmodifizierung e.V., 04318 Leipzig, Germany and Institut für Experimentelle, Physik II, Universität Leipzig, 04103 Leipzig, Germany

O. Buiu

University of Liverpool, Liverpool L69 3GJ, United Kingdom

S. Hall

University of Liverpool, Liverpool L69 3GJ, United Kingdom

Mathias Schubert

University of Nebraska - Lincoln, mschubert4@unl.edu

Follow this and additional works at: https://digitalcommons.unl.edu/mrsecfacpubs

Part of the Materials Science and Engineering Commons

Bundesmann, C.; Buiu, O.; Hall, S.; and Schubert, Mathias, "Dielectric constants and phonon modes of amorphous hafnium aluminate deposited by metal organic chemical vapor deposition" (2007). Faculty Publications: Materials Research Science and Engineering Center. 73.

https://digitalcommons.unl.edu/mrsecfacpubs/73

This Article is brought to you for free and open access by the Materials Research Science and Engineering Center at DigitalCommons@University of Nebraska - Lincoln. It has been accepted for inclusion in Faculty Publications: Materials Research Science and Engineering Center by an authorized administrator of DigitalCommons@University of Nebraska - Lincoln. 


\title{
Dielectric constants and phonon modes of amorphous hafnium aluminate deposited by metal organic chemical vapor deposition
}

\author{
C. Bundesmann ${ }^{\text {a) }}$ \\ Leibniz-Institut für Oberflächenmodifizierung e.V., 04318 Leipzig, Germany and Institut für Experimentelle \\ Physik II, Universität Leipzig, 04103 Leipzig, Germany \\ O. Buiu and S. Hall \\ Department of Electrical Engineering and Electronics, University of Liverpool, Liverpool L69 3GJ, \\ United Kingdom \\ M. Schubert \\ Department of Electrical Engineering, University of Nebraska-Lincoln, 68588-0511 Lincoln, Nebraska, USA
}

(Received 6 June 2007; accepted 31 August 2007; published online 21 September 2007)

\begin{abstract}
Dielectric constants and long-wavelength optical phonon modes of amorphous hafnium aluminate films with a maximum aluminum content of 19 at. \% are studied by infrared spectroscopic ellipsometry (IRSE). The hafnium aluminate films were prepared by metal organic chemical vapor deposition on silicon substrates. IRSE revealed one polar lattice mode and one impurity-type mode, which show all a systematic shift in frequency with varying $\mathrm{Al}$ content. The static dielectric constant decreases from 10.1 for 4.6 at. \% Al to 8.1 for 19 at. \% Al. The absolute values were found to be between $50 \%$ and $70 \%$ smaller than the values obtained from electrical measurements. (C) 2007 American Institute of Physics. [DOI: 10.1063/1.2787962]
\end{abstract}

The continuous scaling of metal oxide semiconductor field effect transistors is accompanied by a reduction of the gate oxide thickness. $\mathrm{SiO}_{2}$ has been the gate dielectric material of choice for decades, but a thickness below $1-1.5 \mathrm{~nm}$ will generate an excessive leakage current, which will compromise the performance and functionality of the devices. A promising candidate for replacing $\mathrm{SiO}_{2}$ is $\mathrm{HfO}_{2} \cdot \mathrm{HfO}_{2}$ is a dielectric material with a static dielectric constant (17-25), with a relatively high free energy of reaction with $\mathrm{Si}$ (47.6 kcal/mole at $T=727^{\circ} \mathrm{C}$ ) as compared to $\mathrm{TiO}_{2}$ and $\mathrm{Ta}_{2} \mathrm{O}_{5}$, and its relatively large band gap $(5.33-5.9 \mathrm{eV}) .^{1-3}$

For minimization of electrical and mass transport along grain boundaries and stabilization of the $\mathrm{Si}$-metal oxide interface, it is preferable that the gate oxide remains amorphous throughout complementary metal oxide semiconductor processing. Unfortunately, amorphous $\mathrm{HfO}_{2}$ films deposited at low temperatures crystallize during postdeposition annealing. $\mathrm{HfO}_{2}$ films deposited by metal organic chemical vapor deposition (MOCVD) at higher temperatures or atomic layer deposition typically exhibit a polycrystalline structure. A possible solution is to alloy $\mathrm{HfO}_{2}$ with $\mathrm{Al}_{2} \mathrm{O}_{3}$ to form hafnium aluminate, which retains a high relative dielectric constant of $\varepsilon_{r} \sim 15$ and remains amorphous up to high processing temperatures, for example, up to $T=900{ }^{\circ} \mathrm{C}$ for an $\mathrm{Al}$ content of 31 at. $\%{ }^{4}$

Furthermore, the incorporation of $\mathrm{Al}$ will reduce-in the first instance $(6.8$ at. \% Al) — the leakage current measured on as deposited samples. However, a high $\mathrm{Al}$ concentration (e.g., above 31.7 at. \%) can result in an increase of the leakage current by two orders of magnitude. $\mathrm{HfO}_{2}-\mathrm{Al}_{2} \mathrm{O}_{3}$ nanolaminates or multilayer structures have also received recently much attention as they potentially combine the advantages of $\mathrm{HfO}_{2}$ (thermodynamic stability on $\mathrm{Si}$ and high dielectric constant) with those of $\mathrm{Al}_{2} \mathrm{O}_{3}$ (large band gap of $E_{g} \sim 8.8 \mathrm{eV}$, large band offset, good barrier properties). These layers are

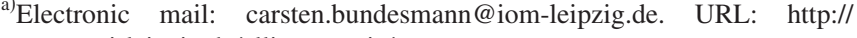
www.uni-leipzig.de/ellipsometrie/
}

also of specific interest for the realization of metal-insulatormetal capacitors, a key passive device in Si radio-frequency or mixed signal integrated circuit applications.

This work presents studies of the infrared (IR) active optical phonon modes and dielectric constants of amorphous hafnium aluminate films with a maximum $\mathrm{Al}$ content of 19 at. \% by infrared spectroscopic ellipsometry (IRSE). Optical studies of $\mathrm{HfO}_{2}$ in the infrared spectral range were reported previously. For example, transmission intensity measurements were done for $\mathrm{HfO}_{2}-\mathrm{SiO}_{2}$ films grown by chemical solution deposition (CSD) on $\mathrm{Si}$ (Ref. 7) or $\mathrm{HfO}_{2}$ films grown by chemical vapor deposition on $\mathrm{Si} / \mathrm{SiO}_{x} \mathrm{~N}_{y}$. Sintered pellets of $\mathrm{ZrO}_{2}-\mathrm{HfO}_{2}$ solid solutions were studied by reflection intensity measurements. ${ }^{9}$ Furthermore, phonon mode properties were studied in $\mathrm{HfO}_{2}$ powder and in Eudoped $\mathrm{HfO}_{2}$ sol-gel films by Raman scattering. ${ }^{10}$ Firstprinciples studies of structural, vibrational, and lattice dielectric properties of $\mathrm{HfO}_{2}$ were reported. ${ }^{11}$ No free-chargecarrier contributions were experimentally identified, but contributions from IR resonance vibrations could be extracted for monoclinic or amorphous $\mathrm{HfO}_{2}$. Infrared spectra of hafnium aluminate films have not been reported yet. The lack of previous reports and a potential source of information for future investigation of device structures has motivated the present ellipsometry study of the infrared optical response of hafnium aluminate films on silicon. Note that IRSE can be, in principle, applied to determine the properties of very thin films despite the fact that light wavelengths exceed the layer thickness by several orders of magnitude. ${ }^{12}$

Hafnium aluminate films were deposited on Si substrates by liquid injection MOCVD with an Aixtron AIX 200FE Atomic Vapor Deposition (AVD ${ }^{\mathrm{TM}}$ ) reactor fitted with a "Trijet"TM injector system. The $\mathrm{Hf}$ and $\mathrm{Al}$ precursors are $\left[\mathrm{Hf}\left(\mathrm{OCMe}_{2} \mathrm{CH}_{2} \mathrm{OMe}\right)_{2}\right]$ and $\left[\mathrm{Al}\left(\mathrm{OPr}^{i}\right)_{3}\right]$, respectively. The precursors are dissolved in heptane at a concentration of $0.1 M$. A constant injection rate of $\left[\mathrm{Hf}(\mathrm{mmp})_{4}\right]$ was used, while the $\left[\mathrm{Al}\left(\mathrm{OPr}^{i}\right)_{3}\right]$ mole fraction was varied. The substrate and evaporator temperatures were $T=500{ }^{\circ} \mathrm{C}$ and 


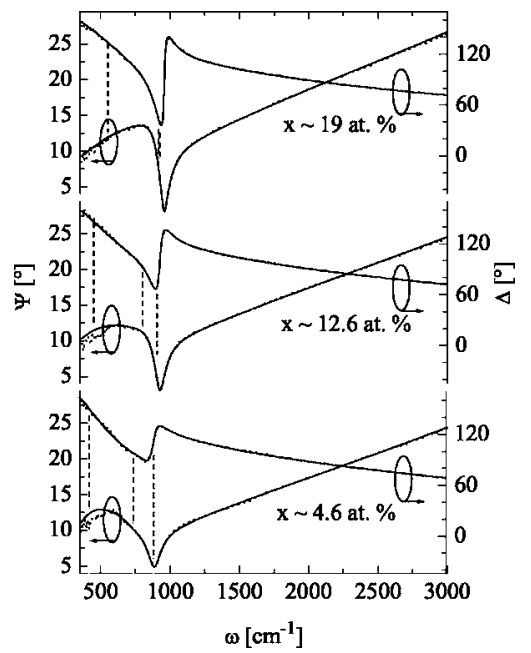

FIG. 1. Experimental (dotted lines) and best-match calculated (solid lines) IRSE $\Psi$ and $\Delta$ spectra of hafnium aluminate films on silicon. The angle of incidence is $\Phi_{a}=70^{\circ}$. TO, LO, and IM modes are indicated by vertical dashed lines.

$T=200{ }^{\circ} \mathrm{C}$, respectively. The reactor pressure was $p=5$ mbars, and the argon and oxygen flow was chosen to be 200 and 100 SCCM (SCCM denotes cubic centimeter per minute at STP) respectively. The concentrations of the precursors were carefully monitored during the deposition. The homogeneity and $\mathrm{Al}$ content of the films were determined by spectroscopic ellipsometry in the ultraviolet and visible spectral regions and by Auger spectroscopy, respectively. ${ }^{13}$

Spectroscopic ellipsometry is a well-known technique for the determination of the dielectric function (DF) and thickness $d$ of thin films within layered samples. ${ }^{12}$ The ellipsometric parameters $\Psi$ and $\Delta$ are related to the complex reflectance ratio $\rho=r_{p} / r_{s}=\tan \Psi \exp (i \Delta)$, where $r_{p}$ and $r_{s}$ are the reflection coefficients for light polarized parallel $(p)$ and perpendicular $(s)$ to the plane of incidence, respectively. IRSE spectra are analyzed by a model analysis using a model dielectric function (MDF). The IR DF is sensitive to phonon and free-carrier contributions. The hafnium aluminate films were highly electrically resistive, and no free-charge-carrier contributions were detected. Hence, the following MDF is used. $^{12}$

$$
\varepsilon(\omega)=\varepsilon_{\infty} \frac{\omega_{\mathrm{LO}}^{2}-\omega^{2}-i \gamma_{\mathrm{LO}} \omega}{\omega_{\mathrm{TO}}^{2}-\omega^{2}-i \gamma_{\mathrm{TO}} \omega}\left(1+\frac{i \delta \gamma-\delta \omega^{2}}{\omega^{2}+i \gamma_{\mathrm{TO}, \mathrm{IM}} \omega-\omega_{\mathrm{IM}}}\right) .
$$

Equation (1) considers electronic contributions by including the high-frequency MDF limit $\varepsilon_{\infty}$ and contributions due to one lattice and one impurity-type mode. An anharmonic oscillator with Lorentzian broadening is used to describe the polar lattice mode, which splits into transverse optical (TO, frequency $\omega_{\mathrm{TO}}$, broadening parameter $\gamma_{\mathrm{TO}}$ ) and longitudinal optical $\left(\mathrm{LO}, \omega_{\mathrm{LO}}, \gamma_{\mathrm{LO}}\right)$ phonons. The impurity-type mode (IM, $\left.\omega_{\mathrm{IM}} \equiv \omega_{\mathrm{TO}, \mathrm{IM}}\right)$ describes modes with low polarity, which contribute to the DF as a small perturbation only. ${ }^{14,15}$ Lattice imperfections or alloying disorder can induce subtle modes of small polarity. Equation (1) holds for the frequencies $\delta \omega^{2}=\omega_{\mathrm{LO}, \mathrm{IM}}^{2}-\omega_{\mathrm{TO}, \mathrm{IM}}^{2}$ and the broadening parameters $\delta \gamma$ $\equiv \gamma_{\mathrm{LO}, \mathrm{IM}}-\gamma_{\mathrm{TO}, \mathrm{IM}}$. IRSE spectra were recorded with an IR WVASE (J. A. Woollam Inc.) at room temperature, with a spectral resolution of $8 \mathrm{~cm}^{-1}$, in the spectral range from
TABLE I. Best-match MDF parameters and film thickness $d$ for the hafnium aluminate films. Error bars in parentheses represent the $90 \%$ confidence limits.

\begin{tabular}{lccc}
\hline \hline & $\begin{array}{c}\text { SI 64 } \\
(4.6 \text { at. \% Al) }\end{array}$ & $\begin{array}{c}\text { SI 58 } \\
(12.8 \text { at. \% Al) }\end{array}$ & $\begin{array}{c}\text { SI 60 } \\
(19 \text { at. \% Al) }\end{array}$ \\
\hline$\varepsilon_{\infty}$ & $3.339(0.008)$ & $3.089(0.008)$ & $2.916(0.008)$ \\
$\omega_{\mathrm{TO}}\left(\mathrm{cm}^{-1}\right)$ & $419(4)$ & $448(5)$ & $553(4)$ \\
$\gamma_{\mathrm{TO}}\left(\mathrm{cm}^{-1}\right)$ & $317(6)$ & $476(11)$ & $614(18)$ \\
$\omega_{\mathrm{LO}}\left(\mathrm{cm}^{-1}\right)$ & $733(3)$ & $803(3)$ & $921(7)$ \\
$\gamma_{\mathrm{LO}}\left(\mathrm{cm}^{-1}\right)$ & $383(5)$ & $624(14)$ & $796(21)$ \\
$\omega_{\mathrm{IM}}\left(\mathrm{cm}^{-1}\right)$ & $881.2(0.9)$ & $907.0(0.5)$ & $925.0(0.3)$ \\
$\gamma_{\mathrm{TO}, \mathrm{IM}}\left(\mathrm{cm}^{-1}\right)$ & $227(7)$ & $304(6)$ & $373(7)$ \\
$\gamma_{\mathrm{LO}, \mathrm{IM}}\left(\mathrm{cm}^{-1}\right)$ & $139(3)$ & $132(2)$ & $124.0(0.8)$ \\
$d(\mathrm{~nm})$ & $291.4(0.3)$ & $293.5(0.3)$ & $322.5(0.4)$ \\
$\varepsilon_{0}{ }^{a}$ & 10.2 & 9.92 & 8.09 \\
\hline \hline
\end{tabular}

$\overline{{ }^{\mathrm{a}} \text { Calculated from } \varepsilon_{\infty}, \omega_{\mathrm{TO}} \text {, and } \omega_{\mathrm{LO}} \text { by the Lydanne-Sachs-Teller relation }}$ [Eq. (2)].

360 to $3000 \mathrm{~cm}^{-1}$, and at two angles of incidence $\Phi_{a}=70^{\circ}$ and $75^{\circ}$.

The static dielectric constant $\varepsilon_{0}$ can be calculated from $\varepsilon_{\infty}, \omega_{\mathrm{TO}}$, and $\omega_{\mathrm{LO}}$ by the Lydanne-Sachs-Teller relation

$$
\varepsilon_{0}=\varepsilon_{\infty} \prod_{i=1}^{l} \omega_{\mathrm{LO}, i}^{2} / \omega_{\mathrm{TO}, i}^{2} .
$$

The static dielectric constant $\varepsilon_{0}$ can be referred to the relative dielectric constant $\varepsilon_{r}$, for which the notations $k$ or $\kappa$ are also often used in the literature.

Figure 1 shows the IRSE spectra of the hafnium aluminate films on silicon. A good agreement between experimental and model data can be seen. The IRSE analysis revealed one polar lattice mode and one impurity-type mode. The frequencies of the lattice mode and of the aluminium-induced impurity mode reveal a consistent blueshift with increasing Al content. This blueshift reflects the substantial decrease of the host lattice mass by substitution of $\mathrm{Hf}$ (molar mass of 178.5) with $\mathrm{Al}$ (molar mass of 26.98). Table I summarizes the best-match model parameters. In Fig. 2, the phonon mode frequencies and broadening parameters are plotted versus $\mathrm{Al}$ content. A systematic, almost linear shift with $\mathrm{Al}$ content can be seen for all parameters. The extrapolation to $x$ $=0$ yields $\omega_{\mathrm{TO}} \sim 360 \mathrm{~cm}^{-1}, \quad \omega_{\mathrm{LO}} \sim 660 \mathrm{~cm}^{-1}, \quad$ and $\omega_{\mathrm{IM}}$ $\sim 870 \mathrm{~cm}^{-1}$. Neumayer and Cartier observed a broad absorption band between $\omega=200 \mathrm{~cm}^{-1}$ and $\omega=600 \mathrm{~cm}^{-1}$ centered at $\omega=355 \mathrm{~cm}^{-1}$ for amorphous $\mathrm{HfO}_{2}$ films prepared by CSD. The center frequency agrees well with our extrapolated $\omega_{\mathrm{TO}} \sim 360 \mathrm{~cm}^{-1}$. Upon annealing up to $T=1200{ }^{\circ} \mathrm{C}$, Neumayer and Cartier observed a transformation from amorphous to monoclinic $\mathrm{HfO}_{2}$, which resulted in the occurrence of ten absorption bands between $\omega=183 \mathrm{~cm}^{-1}$ and $\omega=752 \mathrm{~cm}^{-1}$. These results confirm the amorphous structure of our hafnium aluminate films. IRSE measurements of phonon mode frequencies allow us to estimate the amount of incorporated Al. The increment of the broadening parameters with increasing $\mathrm{Al}$ content is assigned to the increasing disorder due to alloying.

In Fig. 3, the high-frequency dielectric constants $\varepsilon_{\infty}$, as determined by IRSE, and the static dielectric constants $\varepsilon_{0}$ calculated by the Lydanne-Sachs-Teller relation [Eq. (2)], are summarized. For both $\varepsilon_{\infty}$ and $\varepsilon_{0}$, a systematic decrease with increasing $\mathrm{Al}$ content can be seen. The same trend was found 

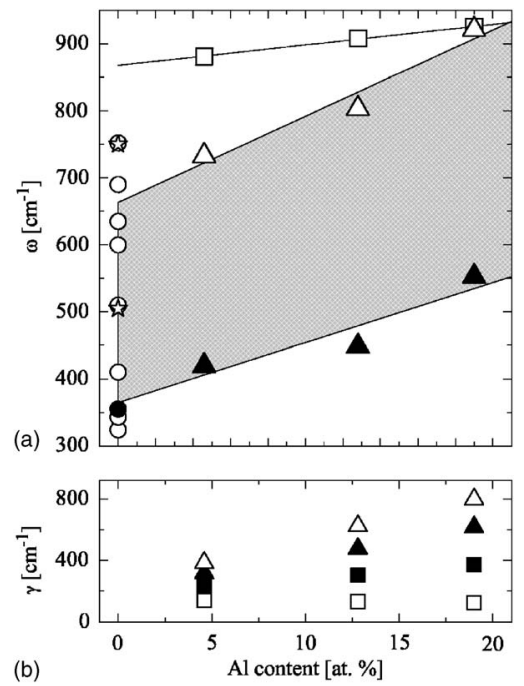

FIG. 2. Best-match phonon mode frequencies [panel (a)] and broadening parameters [panel (b)] versus Al content of the IM (open/solid squares), TO (solid triangles), and LO modes (open triangles), as determined by IRSE. The shaded area marks the band of total reflection. The solid lines are linear approximations. Solid circle, open circles, and asterisks mark phonon modes of an amorphous $\mathrm{HfO}_{2}$ film (Ref. 7), monoclinic $\mathrm{HfO}_{2}$ films (Ref. 7), and monoclinic $\mathrm{HfO}_{2}$ crystallites in an amorphous matrix (Ref. 8), respectively.

in $C-V$ measurements on the same samples. ${ }^{13,16}$ However, the dielectric constants were found to be higher (between $50 \%$ and $70 \%$ ) than reported here. The strong discrepancy between the static dielectric constants from previous electrical and present infrared measurements is not clear at this point. Experimental conditions under which the quantities are determined affect the accuracy of the results. For instance, contact preparation, interface, and built-in charges can result in an apparent increase of the material's relative dielectric constant from electrical measurements. Furthermore, the evaluation of the previous $C-V$ data analysis cannot be fully correct because erroneous thickness values were assumed due to an interface region which cannot be accessed. Therefore, the $C-V$ data represent only effective dielectric constant values. Note also that the electrical measurements were typically done at low frequencies between 50 and $100 \mathrm{kHz}$, which correspond to wavenumbers between $1.7 \times 10^{-6}$ and $3.3 \times 10^{-6} \mathrm{~cm}^{-1}$ or wavelengths between $6 \times 10^{9}$ and $3 \times 10^{9} \mu \mathrm{m}$.

Infrared optical studies are known to be an accurate and appropriate tool for the determination of the static and highfrequency dielectric constants. Infrared ellipsometry, which determines thickness and optical constants from semiconductor thin films independently, has been proven very recently to yield accurate results of the static and high-frequency dielectric constants for numerous semiconductor materials and thin film structures. ${ }^{12}$ Recently, Momida et al. presented firstprinciples studies of the dielectric constants of amorphous hafnium aluminate. ${ }^{17}$ They reported also values larger than our IRSE results. They found that the dielectric constant is dominated by lattice polarizations with large contributions from low-frequency phonon modes with a frequency less than $200 \mathrm{~cm}^{-1}$. Indeed, strong acoustic or optical polarizability modes with frequencies below the spectral range studied here could result in a further increase of the static dielectric constant. However, no indication of such modes was seen here; even measurements with a far-infrared ellipsometry
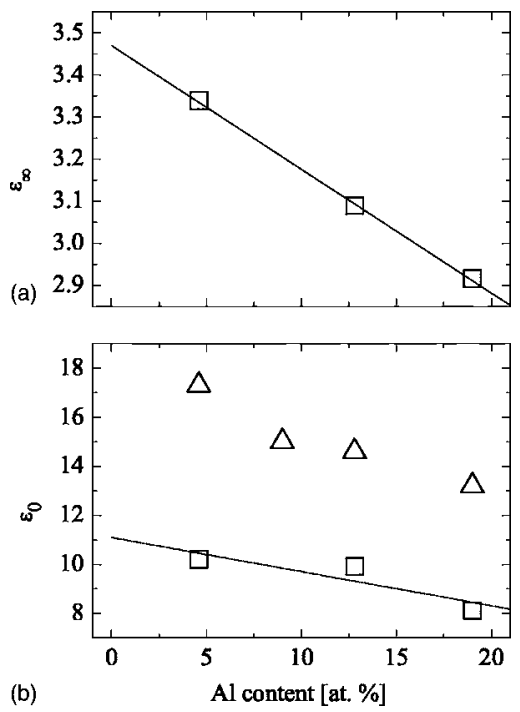

FIG. 3. Best-match high-frequency dielectric constant parameters (a) and calculated static dielectric constants (b) versus $\mathrm{Al}$ content, as determined by IRSE (squares). The solid lines are linear approximations. Triangles in (b) represent effective relative dielectric constants from $C-V$ measurements Ref. 13 and 16.

setup in the spectral range from 150 to $600 \mathrm{~cm}^{-1}$ did not show additional modes.

O.B. and S.H. acknowledge the support of the Engineering and Physical Sciences Research Council (EPSRC), U.K. M.S. acknowledges startup funds from the College of Engineering at the University of Nebraska-Lincoln, support from the J.A. Woollam Foundation, and the National Science Foundation in MRSEC QSPIN. The authors also thank Paul Chalker (University of Liverpool) and Heiner Gottlob (AMO $\mathrm{GmbH}$, Aachen) for sample preparation, and Tino Hofmann (UNL) for fruitful discussions and technical help.

${ }^{1}$ A. Callegari, E. Cartier, M. Gribelyuk, H. F. Okorn-Schmidt, and T. Zabel, J. Appl. Phys. 90, 6466 (2001).

${ }^{2}$ T. Kauerauf, B. Govoreanu, R. Degraeve, G. Groeseneken, and H. Maes, Solid-State Electron. 49, 695 (2005).

${ }^{3}$ E. P. Gusev, C. Cabral, Jr., M. Copel, C. D'Emic, and M. Gribelyuk, Microelectron. Eng. 69, 145 (2003).

${ }^{4}$ W. J. Zhu, T. Tamagawa, M. Gibson, T. Furukawa, and T. P. Ma, IEEE Electron Device Lett. 23, 649 (2002).

${ }^{5}$ H. Hu, C. Zhu, X. Yu, A. Chin, M. F. Li, B. J. Cho, D.-L. Kwong, P. D. Foo, M. B. Yu, X. Lu et al., IEEE Electron Device Lett. 24, 60 (2003).

${ }^{6}$ S. J. Ding, H. Hu, C. Zhu, S. J. Kim, X. Yu, M. F. Li, B. J. Cho, D. Chan, M. B. Yu, S. C. Rustagi et al., IEEE Trans. Electron Devices 51, 886 (2004).

${ }^{7}$ D. A. Neumayer and E. Cartier, J. Appl. Phys. 90, 1801 (2001).

${ }^{8}$ M. M. Frank, S. Sayan, S. Dörmann, T. J. Emge, L. S. Wielunski, E. Garfunkel, and Y. J. Chabal, Mater. Sci. Eng., B 109, 6 (2004).

${ }^{9}$ T. Hirata, Phys. Rev. B 50, 2874 (1994).

${ }^{10}$ M. Villanueva-Ibanez, C. L. Luyer, O. Marty, and J. Mugnier, Opt. Mater. (Amsterdam, Neth.) 24, 51 (2003).

${ }^{11}$ X. Zhao and D. Vanderbilt, Phys. Rev. B 65, 233106 (2002).

${ }^{12} \mathrm{M}$. Schubert, Infrared Ellipsometry on Semiconductor Layer Structures: Phonons, Plasmons, and Polaritons (Springer, New York, 2004).

${ }^{13}$ O. Buiu, Y. Lu, S. Hall, I. Z. Mitrovic, R. J. Potter, and P. R. Chalker, Thin Solid Films 515, 3772 (2007).

${ }^{14}$ A. Kasic, M. Schubert, S. Einfeldt, D. Hommel, and T. E. Tiwald, Phys. Rev. B 62, 7365 (2000).

${ }^{15}$ C. Bundesmann, A. Rahm, M. Lorenz, M. Grundmann, and M. Schubert, J. Appl. Phys. 99, 113504 (2006).

${ }^{16}$ Y. Lu, O. Buiu, S. Hall, I. Z. Mitrovic, W. Davey, R. J. Potter, and P. R. Chalker, Microelectron. Reliab. 47, 722 (2007).

${ }^{17}$ H. Momida, T. Hamada, Y. Takagi, T. Yamamoto, T. Uda, and T. Ohno, Phys. Rev. B 75, 195105 (2007). 